\title{
Dual band microstrip antenna with non regular polygonal patch for satellite applications
}

\author{
Mohammad Mosalanejad $^{1 \mathrm{a})}$, Ali Farahbakhsh ${ }^{2 \mathrm{~b}}$, \\ and Gholamreza Moradi ${ }^{1 \mathrm{c})}$ \\ ${ }^{1}$ Wave Propagation and Microwave Research Lab, \\ Electrical Engineering Department, Amirkabir University of Technology, \\ Tehran, Iran \\ ${ }^{2}$ Electrical Engineering Department, Iran University of Science and Technology, \\ Tehran, Iran \\ a)mosalanejad@aut.ac.ir \\ b)farahbakhsh@ib-eco.com \\ c)ghmoradi@aut.ac.ir
}

\begin{abstract}
In this paper, a new method for designing dual band microstrip antenna is presented. This method can be used to design any dual band microstrip patch antenna with arbitrary resonant frequencies and different frequency ratios. In this method, non-regular polygonal patch is used to design dual band microstrip antenna and particle swarm optimization (PSO) technique and ant colony optimization (ACO) are used to optimize the shape of the patch antenna. This method is used to design a dual band microstrip antenna for satellite application, which has resonant frequencies at 8.6 and $13 \mathrm{GHz}$.
\end{abstract}

Keywords: ant colony optimization, dual band microstrip antenna, particle swarm optimization, satellite application

Classification: Microwave and millimeter wave devices, circuits, and systems

\section{References}

[1] D. M. Pozar and D. H. Schaubert, Microstrip antennas-the analysis and design of microstrip antennas and arrays, IEEE Press, New York, 1995.

[2] K. F. Lee and W. Chen, Advances in microstrip and printed antennas, John Wiley and Sons, 1997.

[3] R. Garg, P. Bhartia, I.J. Bahl, and A. Ittipiboon, Microstrip antenna design handbook, Artech House, Dedham, 2000.

[4] Z. N. Chen, Antennas for Portable Devices, John Wiley \& Sons, 2007.

[5] K. P. Yang and K. L. Wong, "Dual-band circularly polarized square microstrip antenna," IEEE Trans. Antennas Propag., vol. 49, no. 3, pp. 377-382, March 2001.

[6] J. Y. Jan and K. L. Wong, "A dual-band circularly polarized stacked elliptic microstrip antenna," Microw. Opt. Technol. Lett., vol. 24, no. 5, pp. 354-357, March 2000. 
[7] S. H. S. Esfahlani, A. Tavakoli, and P. Dehkhoda, "A Compact SingleLayer Dual-Band Microstrip Antenna for Satellite Applications," IEEE Antennas Wireless Propag. Lett., vol. 10, 2011.

[8] Y.-K. Jung and B. Lee, "Dual-Band Circularly Polarized Microstrip RFID Reader Antenna Using Metamaterial Branch-Line Coupler," IEEE Trans. Antennas Propag., vol. 60, no. 2, pp. 786-791, Feb. 2012.

[9] H.-D. Chen, J.-S. Chen, and Y.-T. Cheng, "Modified inverted-L monopole antenna for $2.4 / 5 \mathrm{GHz}$ dual-band operations," IEE Electron. Lett., vol. 39, no. 22, Oct. 2003.

[10] R. K. Raj, M. Joseph, C. K. Aanandan, and K. Vasudevan, "A New Compact Microstrip-Fed Dual-Band Coplanar Antenna for WLAN Applications," IEEE Trans. Antennas Propag., vol. 54, no. 12, pp. 3755-3762, Dec. 2006.

[11] S. C. Chen, G. C. Liu, X. Y. Chen, T. F. Lin, X. G. Liu, and Z. Q. Duan, "Compact Dual-Band GPS Microstrip Antenna Using Multilayer LTCC Substrate," IEEE Antennas Wireless Propag. Lett., vol. 9, 2010.

[12] D. H. Choi, Y. J. Cho, and S. O. Park, "Dual-band and dual-polarised microstripantenna," Electronics Lett., vol. 42, no. 2, Jan. 2006.

[13] F. Ferrero, C. Luxey, G. Jacquemod, and R. Staraj, "Dual-Band Circularly Polarized Microstrip Antenna for Satellite Applications," IEEE Antennas Wireless Propag. Lett., vol. 4, 2005.

[14] A. Farahbakhsh and G. Moradi, "Design a Low Mutual Coupling Microstrip Array Antenna with Non Regular Polygonal Patches by GA and ACO," IEICE Electron. Express, vol. 7, no. 17, pp. 1271-1275, 2010.

[15] A. Farahbakhsh, G. Moradi, and S. Mohanna, "Reduction of Mutual coupling in Microstrip Array Antenna using Polygonal Defected Ground Structure," ACES Journal, vol. 26, no. 4, pp. 334-339, April 2011.

[16] J. Kennedy and R. C. Eberhart, "Particle swarm optimization," Proc. IEEE Conf. on Neural Networks, pp. 1942-1948, Piscataway, USA, 1995.

[17] M. Dorigo and G. D. Caro, "The Ant Colony Optimization metaheuristic," in New Ideas in Optimization, D. Corne et al., Eds., McGrawHill, London, pp. 11-32, 1999.

[18] A. Farahbakhsh, S. Tavakoli, and A. Seifolhosseini, "Enhancement of Genetic Algorithm and Ant Colony Optimization Techniques using Fuzzy Systems," IEEE International Advance Computing Conference, March 2009.

[19] FEKO 6.1, Copyright 2005-2012, EM Software \& Systems-S.A. (Pty) Ltd.

\section{Introduction}

Due to fast development of communications, design of small, low cost, simple manufacturing, light weight and conformable antennas is very important. In this case, a microstrip antenna is a good choice $[1,2,3]$. Furthermore, Multiband microstrip antennas are in demand, because they can reduce the cost and size of the communication systems. They are used in lots of applications such as wireless local area network (WLAN), satellite communications and global system for mobile (GSM) [4]. In addition, different types of dual band microstrip patch antennas are presented in literatures such as dual band microstrip antenna with single patch [5] and stacked patches [6] and 
using two separate antennas which are connected to by a shorting pin [7] and using metamaterial branch-line coupler [8]. Chen et al. [9] reported a modified inverted-L monopole with meandered wire and a conducting triangular. A rectangular strip and two lateral strips which are printed on a dielectric substrate are used to design a microstrip dual band antenna for WLAN Applications [10]. In [11], low-temperature cofired ceramic (LTCC) technology is used to design a dual band microstrip antenna for global positioning satellite (GPS) operations. A dual band dual polarized antenna is designed using a microstrip- $\mathrm{T}$ junction and CPW-line for electromagnetically antenna feeding in [12]. A dual band behavior is obtained by inserting a small X-band microstrip patch antenna into a large L-band one [13].

In this paper, a new design method is presented by which, a non-regular polygonal patch is used instead of ordinary patches $[14,15]$ and the shape of the patch is optimized by PSO and ACO algorithms according to the design constraints. The best advantage of this method is that the patch shape is arbitrary and its shape is determined according to the design needs. On the other hand the PSO is a multi-objective algorithm. So, an antenna with any desirable properties can be designed. These properties include antenna resonant frequencies, gain, polarization, input impedance, bandwidth and desirable size. For example in this paper a linear polarized dual band antenna is designed that its gain is greater than $2 \mathrm{~dB}$ and its resonant frequencies are 8.6 and $13 \mathrm{GHz}$.

PSO is a population based stochastic optimization technique developed by Dr. Eberhart and Dr. Kennedy in 1995 [16]. This method was inspired by social behavior of bird flocking or fish schooling. Furthermore, ACO studies artificial systems that take inspiration from the behavior of real ant colonies and are used to solve discrete optimization problems and was introduced by Dorigo et al. in 1999 [17]. The proposed method is used to design a dual band microstrip antenna on Rogers RT/duroid 3003 with relative permittivity of 3 and thickness of $0.813 \mathrm{~mm}$. The resonant frequencies of this antenna are at 8.6 and $13 \mathrm{GHz}$ and can be used for satellite applications. In the next section, the design procedure is studied. Then this method is verified by simulation and measurement.

\section{Design procedure}

In this section, a dual band microstrip antenna for satellite applications is designed. The resonant frequencies of the antenna, as mentioned before, are at 8.6 and $13 \mathrm{GHz}$. This antenna has three conductive layers and two dielectric layers. The conductive layers are patch layer, feed line layer and infinite ground layer, respectively. The thickness of both dielectric layers is the same and is equal to $0.813 \mathrm{~mm}$. The substrate which is used for this antenna is $\mathrm{RT} /$ duroid 3003C, so the relative permittivity of both dielectric layers is 3 , and their relative permabilities are 1 . The patch is fed by proximity coupled mechanism by $50 \Omega$ feed line.

The patch is considered as a polygon with 36 vertexes. According to the 


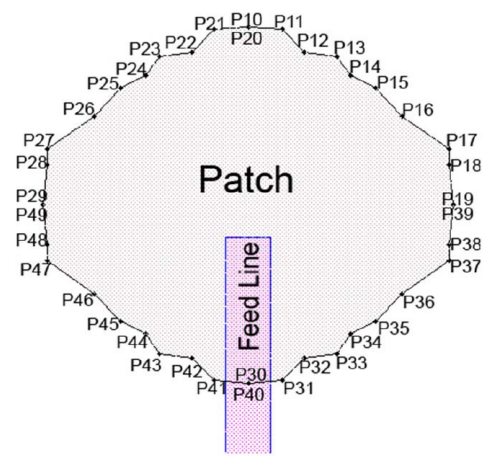

(a)

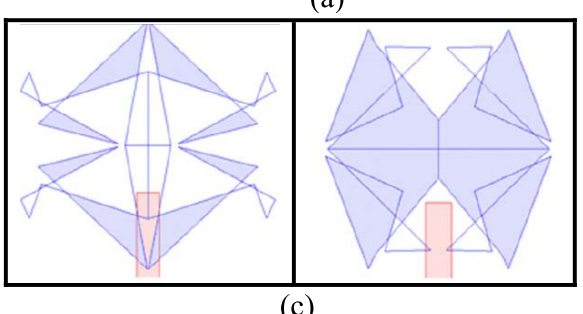

(c)

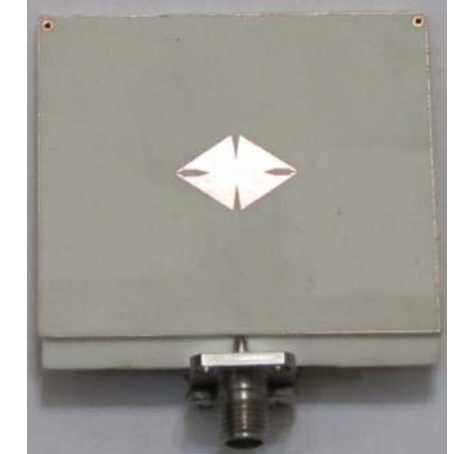

(b)

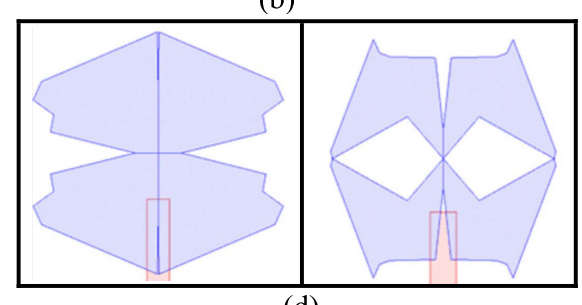

(d)

Fig. 1. (a) Top view of the patch antenna, (b) fabricated patch antenna, (c) invalid patches, (d) validated patches.

application needs, the number of vertexes can be decreased or increased. To simplify the design procedure, it is considered that the patch has vertical and horizontal symmetry. A typical polygonal patch is shown in Fig. 1 (a). In order to have the patch symmetry, positions of vertexes must have the following relations:

$$
P_{1 n}(x, y)=P_{2 n}(-x, y)=P_{3 n}(x,-y)=P_{4 n}(-x,-y)
$$

By considering these symmetries, the patch shape can be determined by finding the positions of 9 vertexes. In the process of designing and optimizing the dual band antenna, there are 21 parameters that should be optimized. These parameters are, $\mathrm{x}$ and $\mathrm{y}$ values of 9 vertexes, feed line width and length, and the intersection between patch and feed line. All of these parameters are optimized by particle swarm optimization technique.

PSO algorithm models swarm behavior, so if there were a bunch of parameters in a specific problem, the values of these parameters move toward the position in the problem space that the best answer for the problem is finally reached. It should be emphasized that the algorithm is continuous, i.e. the particle's parameters can be assigned any value in the defined interval. In this paper, the authors have considered 30 particles to solve the problem. Also, a function that evaluates the position in the solution space is needed, which is called the fitness function. The aim of PSO algorithm is to find the desired antenna by changing the patch shape. In this paper, the desired antenna should have resonant frequencies at 8.6 and $13 \mathrm{GHz}$ and must have good impedance matching and gain at these resonant frequencies. By these requirements, the conditions for the fitness function are defined as follows:

$$
\left|S_{11}\right|_{f 1, f 2} \leq-20 \mathrm{~dB}
$$


where $f_{1}$ and $f_{2}$ are the first and second resonant frequencies. Another constrains can be added to the fitness function such as linear or circular polarization and size limitation. But in this paper only reflection coefficient and gain is considered. Since the PSO algorithm changes the positions of vertexes randomly, if the vertexes of the patch connect to each other in a wrong way, an invalid patch shape will be made as shown in Fig. 1 (c). In this case, enhanced ACO [18] is used to solve this problem and find the correct order of vertexes connection. In enhanced ACO, some artificial ants are generated and then placed on vertexes randomly. The ants' goal is to find the shortest path between the vertexes. In many cases, the shortest path is the path without any intersection between the lines that connect the vertexes. In this case, finding the shortest path is a good idea to find the right path. Ants move randomly form one vertex to another and deposit trail of pheromone on their path according to the path cost. It means, they deposit more pheromone on the shorter path and less pheromone on the ones which have intersection with traveled paths. The ants prefer to travel through the path with more pheromone, So the right path which is the one with more pheromone can be achieved.

According to the above explanations, Fig. $1(\mathrm{c}, \mathrm{d})$ illustrates some invalid patches and validated ones which are processed by enhanced ACO. According to this figure, the patch shapes of group (c) are invalid, because the lines between the vertexes have some intersections. On the other hand, the patch shapes of group (d) are validated patches by enhanced ACO.

This method was run to design a dual band microstrip patch antenna which has resonant frequencies at 8.6 and $13 \mathrm{GHz}$. The fitness of PSO particles, which are dual band microstrip antennas, is calculated by simulation in FEKO software that is based on method of moments (MOM) [19]. The results that are obtained by using this method are listed in Table I.

Table I. Optimization results (all units are in $\mathrm{mm}$ ).

\begin{tabular}{|c|c|c|c|}
\hline $\mathrm{x}_{1}, \mathrm{y}_{1}$ & $\mathrm{x}_{2}, \mathrm{y}_{2}$ & $\mathrm{x}_{3}, \mathrm{y}_{3}$ & $\mathrm{x}_{4}, \mathrm{y}_{4}$ \\
\hline $0.51,4.92$ & $0.0,1.48$ & $0.0,0.0$ & $2.85,0.0$ \\
\hline $\mathrm{x}_{5}, \mathrm{y}_{5}$ & $\mathrm{x}_{6}, \mathrm{y}_{6}$ & $\mathrm{x}_{7}, \mathrm{y}_{7}$ & $\mathrm{x}_{8}, \mathrm{y}_{8}$ \\
\hline $3.27,0.03$ & $4.8,0.48$ & $6.56,0.46$ & $6.79,0.23$ \\
\hline \multicolumn{2}{|c|}{$\mathrm{x}_{9}, \mathrm{y}_{9}$} & \multicolumn{2}{c|}{ Feed line upper width } \\
\hline \multicolumn{2}{|c|}{$7.67,0.01$} & Feed line and patch intersection \\
\hline Feed line lower width & \multicolumn{2}{c|}{1.91} \\
\hline
\end{tabular}

\section{Results and discussion}

In this section, the results of the simulation and measurement of the designed antenna are reported. The fabricated patch is shown in Fig. 1 (b). As can be seen in Fig. 2, the reflection coefficient of this antenna is shown in Fig. 2 (a), the measured gain in $8.6 \mathrm{GHz}$ is shown in Fig. $2(\mathrm{~b})$, and the measured gain 


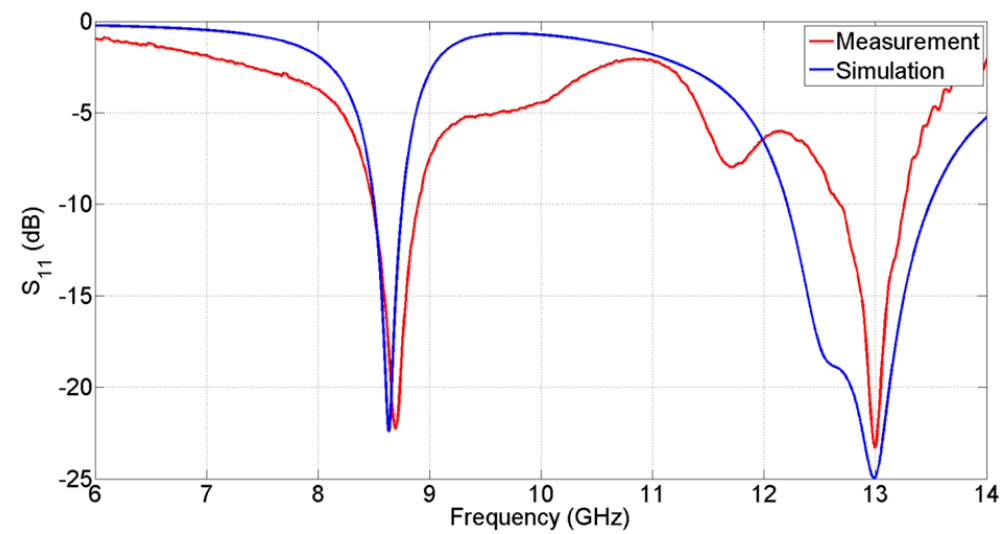

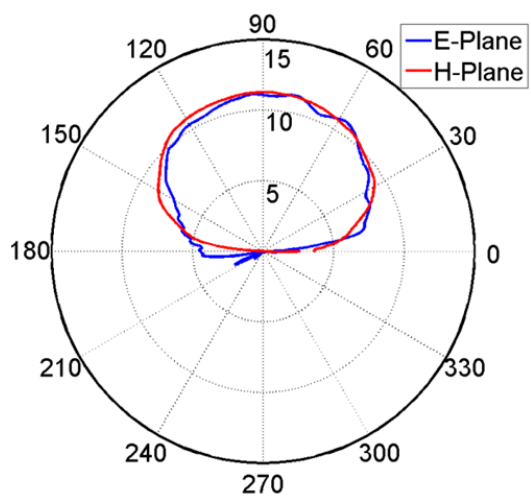

(b) (a)

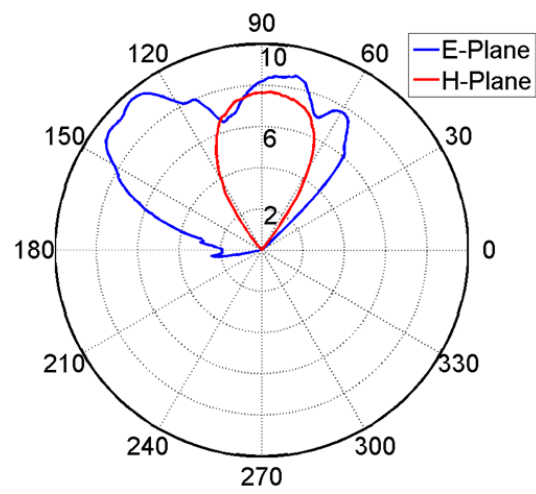

(c)

Fig. 2. (a) Measured and EM simulated $S_{11}$, (b) measured gain radiation pattern for $8.6 \mathrm{GHz}$, (c) measured gain radiation pattern for $13 \mathrm{GHz}$.

in $13 \mathrm{GHz}$ is shown in Fig. 2 (c). According to the first graph, it is obvious that the antenna has two resonant frequencies at $8.6 \mathrm{GHz}$ and $13 \mathrm{GHz}$. The level of $S_{11}$ at $8.6 \mathrm{GHz}$ is about $-22 \mathrm{~dB}$ and at $13 \mathrm{GHz}$ is $-23 \mathrm{~dB}$. As shown in Fig. 2 (a), the antenna has a good $10 \mathrm{~dB}$ bandwidth. The values of bandwidths are about $400 \mathrm{MHz}$ and $500 \mathrm{MHz}$ at resonant frequencies $8.6 \mathrm{GHz}$ and $13 \mathrm{GHz}$ respectively, which satisfies the satellite application needs.

The second and the third graphes in Fig. 2 are the gain of the antenna. Based on these graphes, the gain of the antenna at $8.6 \mathrm{GHz}$ is $11.25 \mathrm{~dB}$ and the gain of the antenna at $13 \mathrm{GHz}$ is about $8 \mathrm{~dB}$. Therefore, the antenna has really good gain at both frequencies. As can be seen in Fig. 2 the simulation and measurement result have a really good agreement.

\section{Conclusion}

A novel method to design dual band microstrip antenna using non regular polygonal patches is proposed. In this method, the antenna patch is considered as a non-regular polygon, and its shape and the physical properties of the feed line are optimized by particle swarm optimization technique. In addition, enhanced ACO is used to process the shapes which are generated by PSO and make the valid shapes from the invalid shapes. As mentioned before, this method can be used to design any antenna with desirable prop- 
erties. In this paper, the proposed method is used to design a dual band microstrip antenna for satellite applications. Simulation and measurement results confirm the fact that this method acts as expected. 